\title{
Airline Partnerships, Antitrust Immunity, and Joint Ventures: What We Know and What I Think We Would Like to Know
}

\author{
Volodymyr Bilotkach ${ }^{1}$
}

Published online: 5 June 2018

(C) The Author(s) 2018

\begin{abstract}
This paper offers an overview of the state of research on airline partnerships and related issues: antitrust immunity, and joint ventures. While at a high level the potential pro- and anti-competitive effects of various forms of airline partnerships are well understood; a number of important gaps in our knowledge remain. For instance, academic research has yet to develop a clear way to differentiate between codesharing with and without immunity, and joint ventures with the use of the conventional IO modelling apparatus. Developing such theoretical models can be useful for policy makers. Future empirical research should focus on understanding the effects of joint ventures - as well as evaluating efficiency benefits of airline partnerships-and determining whether multimarket contact and repeated interaction could have led to the competitive environment that is conducive to tacit collusion.
\end{abstract}

Keywords Airline industry $\cdot$ Alliances $\cdot$ Codesharing $\cdot$ Antitrust immunity $\cdot$ Joint ventures

JEL Classification $\quad \mathrm{D} 43 \cdot \mathrm{L} 13 \cdot \mathrm{L} 40 \cdot \mathrm{L} 93$

\section{Introduction}

The aim of this paper is to take stock of what we know about airline partnerships and their effects on prices and other product characteristics; identify the gaps in our knowledge; and suggest a research agenda for the near future. My key message after reviewing the growing body of work on this subject is: while we have learned a lot,

Volodymyr Bilotkach

volodymyr.bilotkach@newcastle.ac.uk

1 Newcastle University Business School, 5 Barrack Road, Newcastle-upon-Tyne NE1 4SE, UK 
there is a lot of work that remains to be done if we want to be a source of sound policy advice on airline partnerships. Furthermore, the issue of airline cooperation will remain policy-relevant for the foreseeable future.

Alliances between competitors were not invented in the airline industry. Joint ventures, marketing, technology/product licensing, and research and development partnerships can be found in many markets. However, it would not be easy to point to a market where partnerships have become as important as in the airline industry over the last 25 years. Member airlines that belong to the three global alliances carry over half of all passenger traffic worldwide. While only a fraction of these passengers travel on interline itineraries — change operating airline en route-airlines and their passengers also benefit from these partnerships in other ways. The airlines benefit from cost savings due to the joint use of airport facilities and coordinated marketing, while their passengers have the ability to use airlines' loyalty programs on flights and in airport lounges that are operated by partner carriers.

The extent and importance of airline partnerships differ across the markets. In the currently largest segment of global airline industry - the US domestic market- the use of interlining and other forms of partnerships is minimal. Major network carriers-American, United, and Delta - are capable of channelling almost all domestic passenger traffic within their networks-including flights that are operated by both mainline and regional airlines. US domestic partnerships played a somewhat more important role before the merger wave of the last decade; since then, however, interline itineraries in the US market have been a niche product that is used by a small share of passengers.

On the other hand, members of the four joint ventures on the trans-Atlantic market-narrowly defined as the market for travel between the US and the European Economic Area ${ }^{1}$ - control a majority of the seats on non-stop trans-Atlantic flights. While exact extent of interlining within the joint venture networks cannot be ascertained from the publicly available data, we can say that interline itineraries are very common in this market, and many trans-Atlantic links carry predominantly connecting rather than origin-and-destination ${ }^{2}$ passengers. Perhaps more interestingly, the trans-Atlantic market is currently home to various types of airline partnerships: from ad hoc arms' length agreements to cost- and revenue-sharing joint ventures. The latter essentially represents the closest thing to a merger in the current regulatory environment.

Interestingly, there are indeed important gaps in our knowledge on the matter. On the surface, there are no difficult issues: parallel partnerships-those involving overlapping parts of the partners' networks-are anticompetitive, while complementary ones are pro-competitive, as they lead to the removal of double marginalization-a classical result. If we add economies of traffic density to the

\footnotetext{
${ }^{1}$ This includes the European Union plus Switzerland, Norway, and Iceland. We treat the United Kingdom as an EU member for the purposes of this paper, as departure of this country from the European Union will not happen before March of 2019.

${ }^{2}$ In the aviation industry jargon, an origin-and-destination passenger is a passenger who does not connect to or from other flights.
} 
picture, however, partnerships can yield benefits to consumers even on the overlapping parts of the joint network through lower average cost with higher traffic volumes: this is known in Transportation Economics as economies of traffic density. However, current theoretical research does not fully differentiate between different forms of codesharing; between partnerships with and without antitrust immunity; and between partnerships with antitrust immunity and joint ventures. The issue of incremental benefits of deeper levels of cooperation between the airlines is only partly addressed by the empirical body of work. The effects of partnerships on efficiency-much promoted by the partner airlines in their applications for antitrust immunity and joint ventures-have received only cursory attention in the academic literature (due in part to limited data availability on the issue).

As our understanding of the incremental benefits of closer forms of cooperation is limited, we are somewhat in the dark with regard to the effects of the relevant policy options. While earlier studies demonstrated substantial price decreases due to antitrust immunity, more recent work shows only modest gains in this area. Effects of joint ventures are as of yet not studied. It is not clear whether antitrust immunity should be granted in an open-ended fashion as is the case now; or be subject to periodic reviews as some in policy circles have suggested. We also are agnostic as to the implications of repeated interaction and multimarket contact on international routes; there is, however, clear evidence that multimarket contact affects airlines' competitive conduct in the US domestic market.

As full-fledged cross-border mergers in the airline industry are unlikely for the foreseeable future, there will be demand for further work on airline partnerships. I suggest the following lines of inquiry as the most promising here: first, we should gain a better understanding of the implications of different forms of codesharing, and more generally learn to distinguish between different forms of partnerships in our modelling exercises. An evaluation of the incremental benefits of joint ventures appears to be the most fruitful and useful line of inquiry here. Second, as joint ventures currently only include some of the alliance members; they have a potential to disrupt the current equilibrium. Alliance members that are left out of the joint ventures may seek to form different partnerships and joint ventures. Understanding the airlines' incentives in this respect appears to be a promising avenue for future research: both theoretical and empirical. Third, we need to gain a better understanding of the effects of repeated interaction and multimarket contact: we need to understand whether airline partnerships contribute to a tacitly collusive environment in the industry. Last (but not least), I believe that it makes sense to evaluate the effects of partnerships on non-price product characteristics and efficiency-if suitable data become available.

The rest of the paper is organised as follows: in the next section, I introduce the readers to various forms of airline partnerships. This is followed by a review of the relevant literature. Extensive discussion of both pro- and anti-competitive effects of these partnerships is offered next. Afterwards, I discuss the current gaps in research: both theoretical and empirical. Then, I propose a research agenda for the future, and conclude. 


\section{Forms of Airline Partnerships, and Policy Response}

The key policy-relevant forms of airline cooperation include: alliance membership; codesharing; antitrust immunity; and revenue-sharing joint ventures. It is also common in the academic literature and in policy cases to differentiate between parallel and complementary partnerships. The former refer to partnerships that cover the overlapping parts of the partner airlines' networks, whereas the latter apply to interline trips: journeys where the passenger changes carriers en route. This distinction played a crucial role in earlier deliberations that were related to antitrust immunity requests by the British Airways/American Airlines partnership.

For the purposes of this discussion, the term "alliance membership" includes any other cooperative agreements that do not cover direct arrangements between the carriers for sales of seats on partner airlines' flights. Examples include: frequent flier program partnerships; agreements on shared use of airport facilities; joint marketing efforts; etc. Currently, many carriers implement such agreements through their memberships in one of the three global airline alliances; however, ad hoc and even limited cross-alliance partnerships are also not uncommon. ${ }^{3}$ Such arrangements do not affect the pricing of interline itineraries, and may even be entered into by otherwise unrelated carriers: for example, a carrier that flies into a hub airport may subcontract its ground handling to the hubbing airline.

Codesharing generally refers to the airline's including partner airlines' flights into its network, and entering into an arrangement to feed its passengers to the partner airlines' flights. Codesharing agreements can either be route-specific or cover substantial parts of the partner airlines' networks. Codesharing frequently comes hand-in-hand with other alliance-type arrangements—such as frequent flier program partnerships. Not all of the codesharing arrangements occur within the three global alliances; outside of alliance and limited cross-alliance partnerships of this sort do exist.

Codesharing itself takes several forms-depending on the arrangements that the airlines make for actually selling the seats on the partners' flights. Overall, the spectrum of such arrangements ranges from "blocked-space" to "free sale" agreements. While codesharing agreements themselves are not publicly disclosed, it is my understanding from communicating with the people who are familiar with the matter that initially the agreements were predominantly of a "blocked-space" nature, whereas currently airlines within global alliances are moving more towards the "free sale" types of arrangements.

The pricing of interline trips under codesharing arrangements is done in a variety of ways: sometimes a ticketing carrier can have discretion on price setting, with the operating carrier receiving a payment for accepting the passenger from the partner airline. In other cases, the operating carrier sets "sub-fares" for accepting the partner airlines' passengers; these "sub-fares" are added to the total cost of interline

\footnotetext{
${ }^{3}$ For instance, Air France-a Skyteam alliance member-allows its frequent fliers to earn miles on some of the flights that are operated by Finnair (a oneworld alliance carrier) and by Austrian Airlines (a Star Alliance member that is owned by Lufthansa).
} 
itineraries. Under antitrust immunity, partner airlines obtain the explicit right to set the fares jointly for the interline itineraries. Specifics of price-setting for the interline trips are usually not publicly disclosed.

At the basic level, a "blocked space" codesharing agreement specifies a certain number of seats that a partner airline is allowed to sell on a given flight as the latter's own. For instance, a KLM flight from Amsterdam to Berlin would have 10 seats that Delta would be able to sell under its own flight code. One can think about those 10 seats as the virtual Delta Air Lines flight from Amsterdam to Berlin. In the same way, KLM will have the right to sell 20 seats on Delta's Amsterdam to Detroit flight under its own flight code: a virtual KLM flight between the two cities. In the end, if Delta blocks seats on its Amsterdam-Detroit service to, say, five different alliance partners, the Delta flight turns into five virtual flights that are operated by a single aircraft. Under the blocked space codesharing arrangement, each of those virtual flights will have a certain fixed number of seats.

Blocked space agreements are not very flexible. If we return to our example, once KLM has sold its quota of 20 seats, it will be unable to sell further tickets under its flight code-even though it might be able to bring more customers to this flight. Simultaneously, another carrier might be unable to sell its quota-which means that the seats on its virtual flight will remain unoccupied. "Free sale" codesharing arrangements are a way to tackle this problem. One can think about free sale agreements as the same virtual flights as before, but with flexible capacity. Under such an arrangement, if KLM or another codeshare partner with Delta on our hypothetical Amsterdam to Detroit service is able to bring a passenger and sell a seat under its own flight code, this airline obtains the right to sell such a seat as long as the flight is not full. Of course, the "blocked space" and "free sale" arrangements are the two extremes, and in fact some intermediate agreements are also implemented by the codeshare partners.

Multi-airline codesharing agreements led to the emergence of global airline alliances: each of the three current alliances started from a partnership between a US and an EU carrier. Oneworld developed around the partnership between American Airlines and British Airways; SkyTeam evolved from the Delta Air Lines/Air France alliance; and the current Star Alliance is the expanded United Airlines/Lufthansa partnership. The last 10-15 years witnessed a substantial increase in the size and depth of airline alliances in international air transportation.

From a size perspective, more and more individual airlines have decided to join one of the three remaining global airline alliances. For example, while the respective alliances were founded between 1997 and 2000 by a total of 14 airlines, the number of member airlines grew to 52 in 201627 in Star; 13 in SkyTeam; and 12 in oneworld. The alliances currently occupy a dominant position in the global aviation market. Specifically, in 2008 the combined world-wide market share of the three 'mega alliances' was about 59\%. Airline alliances have particularly high market shares_-at least 70\%, based on network capacity—in inter-continental markets, such as the market between North America and Europe.

The nature of the efficiency benefits that stem from codesharing appears to be different from those that are due to alliance membership. Whereas alliance membership mostly reduces the fixed operating costs, codesharing - by attracting additional 
traffic through lower prices for interline itineraries-allows the airlines to take advantage of economies of traffic density.

Antitrust immunity refers to the right of the partner airlines jointly to set the fares within their joint network. This form of cooperation can be viewed as an add-on to codesharing; at this time, all groups of carriers that are covered by antitrust immunity are parts of one of the three airline alliances. Cross-alliance partnerships that are covered by antitrust immunity currently do not exist. The early studies of airline cooperation focused on the possibility of reduced competition by parallel airline partnerships as a result of antitrust immunity. A policy response to this concern has been the carve-outs - or exemption — of overlapping parts of the airline networks from the immunity provision.

Joint ventures can be thought of as a further add-on to multi-carrier partnerships that operate under antitrust immunity. According to the US DOT decision that approved the corresponding joint venture between the key Skyteam alliance partners, the JV was supposed to increase the availability of discounted airfares, as well as to generate additional efficiency benefits. Neither of the two claims have been verified empirically, and I suggest that an analysis of the competitive effects of the trans-Atlantic joint ventures is due.

Given the identified increase in the size and depth of international airline cooperation, the question of whether such a development is in the interest of the consumer immediately suggests itself. Although it is undisputed that consumers gain from airline alliances, it is unclear whether the observed increase in the degree of cooperation is necessary to maximize these benefits. Furthermore, a detailed understanding of the economic effects of airline alliances is pivotal for an overall assessment of their respective costs and benefits for society.

Before we continue, let us take a quick look at the extent of the dominance of airline alliances and joint ventures on the trans-Atlantic market: defined here as the market for commercial passenger air travel between the USA and the European Economic Area. With the use of data from the T100 International Segment dataset, which is collected by the US DOT (this dataset is essentially a census of all commercial flights between the USA and the rest of the world), I calculated annual passenger market shares of the airlines that belong to each of the three global alliances-provided they have at any time been included into a partnership covered by antitrust immunity or joint venture. ${ }^{4}$ Note that the shares are computed for regular scheduled services only; charter flights have been removed from consideration. Figure 1 shows the evolution of the market shares of the key partnerships from 2001 until 2016. I use 2001 as the starting year here because this is the first full year after Skyteam - the youngest of the three current alliances—was founded.

\footnotetext{
${ }^{4}$ For instance, Continental Airlines and US Airways are included in the "other" category here. Even though Continental has been a member of Skyteam alliance, it acted as an independent competitor in the trans-Atlantic market. The same applies to US Airways, which was a Star Alliance member until US Airways' recent merger with American Airlines.
} 


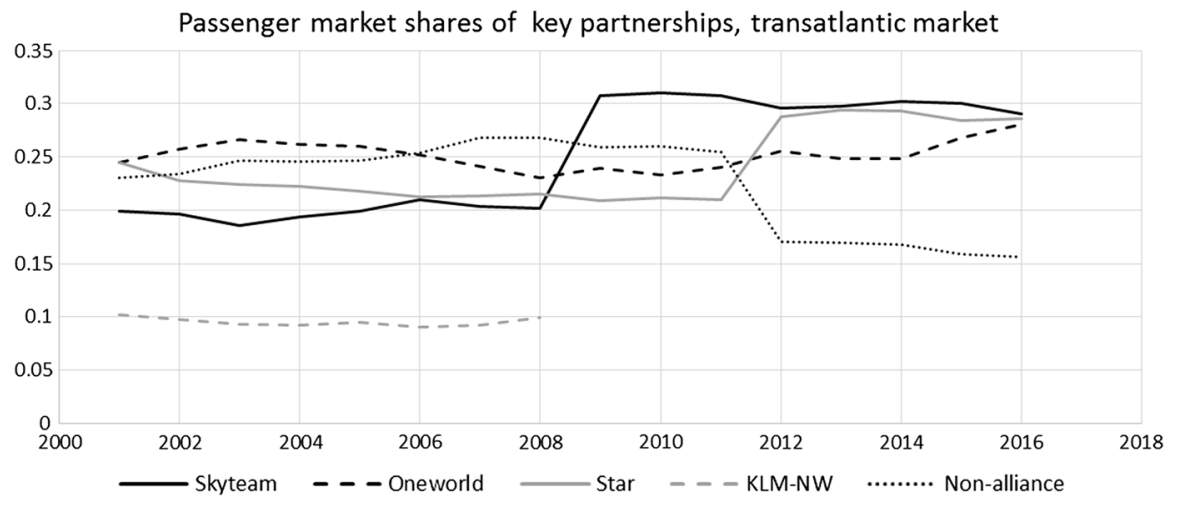

Fig. 1 Market shares of key airline partnerships, US-EU non-stop flights, 2000-2016

Note that before 2008 we have four partnerships in our picture: Northwest-KLM alliance operated as an independent entity until the Delta-Northwest merger, at which time the alliances also merged.

The following facts stand out in Fig. 1: first, $85 \%$ of passengers who cross the Atlantic Ocean in 2016 on non-stop flights between the USA and Europe (admittedly, a small proportion of those passengers started their trips behind these areas and/or continued their journeys beyond them) flew with one of the key alliance members. Second, the largest events that increased the dominance of airline partnerships in this market have been the United/Continental and (to a lesser degree) American/US Airways mergers in 2011 and 2015 respectively. These consolidation events have effectively removed decent-sized independent competitors-Continental Airlines carried $8.7 \%$ of non-stop US-Europe traffic in $2010,{ }^{5}$ and US Airways' market share in 2014 was $4.8 \%$ — from the market. Third, the Delta/Northwest merger — and the subsequent consolidation of the Northwest/KLM partnership into Skyteammade this alliance the largest player on the trans-Atlantic market.

Interestingly, oneworld alliance's market share has been in slow decline for most of the first decade of this century, and started growing afterwards. This could potentially be attributed to the fact that prior to 2010 the American Airlines/British Airways partnership did not have antitrust immunity. Several applications that were made by the partner airlines were declined due to the carriers' joint dominance on the key trans-Atlantic routes (eight out of ten largest trans-Atlantic segments by nonstop passenger traffic include London Heathrow airport as one of their endpoints). When the AA-BA joint venture was approved in 2010, there was a reversal of fortune for the alliance, which was reinforced by the American Airlines/US Airways merger in 2015 .

\footnotetext{
5 This market share made Continental Airlines the fifth-largest airline in the trans-Atlantic market that year.
} 
Last (but not least), since 2010 most of the non-stop trans-Atlantic flights that were operated by the alliance members are also part of respective joint ventures. ${ }^{6}$ Overall, $81 \%$ of the passengers who flew between the USA and Europe in 2016 were on a flight that was operated by one of the joint venture member airlines (87\% if one adds Virgin Atlantic to the list-the airline has a joint venture with Delta, without being a member of either of the three global alliances).

\section{Literature}

The analysis of airline partnerships in the literature has mostly dealt with the price effects of airline cooperation. These studies often do not clearly distinguish between alliances with and without antitrust immunity. The theoretical underpinnings of the functioning of an airline alliance have been developed by Park (1997), Brueckner (2001), Barla and Constantatos (2006) and Czerny (2009). These models treat alliances as effective mergers: the partners maximize joint profits over the networkremoving double marginalisation on interline routes in the process-while obtaining increased market power on overlapping portions of their networks. Efficiency benefits of the partnerships are (where they are modelled) achieved via economies of traffic density, which emerge as lower interline fares increase passenger traffic over the joint network. Bilotkach (2007a) considered a model of an airline that chooses whether to partner with a carrier with a partially overlapping or purely complementary network. Jiang et al. (2015) consider a more complex setup, with four airlines and up to two alliances that are formed endogenously in the model. Chen and Gayle (2007) suggest that the formation of airline alliances could yield market foreclosure. Brueckner and Pels (2005) model consumer welfare effects of consolidation of two alliances; this study was inspired by the joining of KLM/Northwest and Skyteam partnerships following the Air France/KLM merger. Brueckner and Proost (2010) theoretically model the welfare effects of carve-outs.

Models of competition between alliances have been developed by Brueckner and Whalen (2000), Bilotkach (2005), and Flores-Fillol and Moner-Colonques (2007). These models use different assumptions: for example, Bilotkach assumes price competition, while Brueckner and Whalen (2000) consider the case of two alliances that share one hub and compete in quantities. Bilotkach's model is also able to shed some light on the differences between cases of alliances with and without antitrust immunity; the model suggests that immunity will not lead to welfare benefits beyond what can be achieved via codesharing without the partner airlines' coordinating their prices. Zhang and Zhang (2006) propose a more general model of rivalry between alliances, where alliance members are modelled as maximising their profit plus a share of the partner's profit. With the exception of Brueckner and Whalen's model, the theoretical studies of competition between alliances point out that the alliance

\footnotetext{
6 The Skyteam joint venture was approved in 2008, followed by Star Alliance in 2009 and oneworld in 2010. Some of the smaller member airlines-such as SAS and Finnair-are not included in the respective joint ventures, so that the market shares of joint ventures are slightly lower than those of alliances.
} 
members find themselves in a prisoners' dilemma type of situation. When only one alliance is formed, alliance members' profits are higher than if they are out of the alliance. When two alliances are formed, each airline ends up with a lower profit as compared to the situation without alliances. Entering into an alliance thus becomes akin to the defection strategy in the prisoners' dilemma.

While in theory airline partnerships should have an effect on non-price product characteristics, little work has been devoted to evaluating this aspect of alliances. Bilotkach (2007b) models airline alliances that choose prices and the degree of schedule coordination, while Czerny et al. (2016) evaluate the effects of alliances on load factors (the percentage of available seats that are occupied by paying passengers) and aircraft sizes. Adler and Hanany (2016) evaluate the effects of codesharing with and without immunity on prices and flight frequencies. They find that while the airlines are best off with immunity; the passengers' welfare is maximised when the airlines codeshare without antitrust immunity. Additionally, Bilotkach and Hüschelrath (2012) offer a general discussion of the sources of efficiency benefits that are brought about by the airline alliances, with an emphasis on the effects of antitrust immunity on efficiency. Bilotkach and Hüschelrath (2011) provide a more comprehensive survey of the likely effects of antitrust immunity and codesharing.

Not surprisingly, empirical studies of international airline partnerships have mostly focused on price effects (Oum et al. 1996; Park and Zhang 2000; Brueckner and Whalen 2000; Bilotkach 2007c; Whalen 2007; Brueckner 2003; Brueckner et al. 2011). The former two studies essentially compare airfares on routes that are covered by partnerships with those in non-allied markets, while the latter five papers are concerned with measuring the price effects of antitrust immunity as opposed to partnerships without immunity. The general consensus in the literature is that partnerships with immunity benefit interline passengers, who enjoy lower prices. Price decreases tend to be attributed to the removal of double marginalization. However, this is done based on theoretical supposition rather than hard evidence: after all, the specifics of the codesharing agreements_-which would allow shedding more light on the mechanisms behind price decreases - are not publicly available. The general consensus is that antitrust immunity does decrease airfares; however, the magnitude of this effect appears to be declining over time.

Wan et al. (2009) focus on evaluating the price effects of airline partnerships on overlapping parts of the partner airlines' networks. They find that those effects differ across alliances. Zou et al. (2011) also document differences in price-setting across the partnerships. Alderighi et al. (2015) evaluate a sample of offered prices from the European markets. They find that codesharing increases the general price level, and also that the marketing carriers tend to quote higher prices for codeshare services as compared to the operating carriers. Bilotkach and Hüschelrath (2013) find evidence that is consistent with antitrust immunity's leading to market foreclosure: Alliance members increasingly do not accept interline passengers from outside the immunized partnership. In their later work Bilotkach and Hüschelrath (2017) evaluate the incremental effects of joint venture on the partner airline's trans-Atlantic network. The study finds that joint venture partners add capacity on flights between their hubs at the expense of other parts of their network. This finding is supported in part by Fageda et al. (forthcoming). Another interesting finding is that joint venture flights 
feature lower load factors as compared to flights by partner airlines with antitrust immunity outside joint ventures. This can be interpreted as evidence that the promised efficiency benefits of joint ventures have so far failed to be realised.

Codesharing in US domestic markets has also received some attention in the literature. Ito and Lee (2005) present some stylized facts about this practice. In their later paper Ito and Lee (2007) find that most of the codesharing itineraries in the US market are not actually interline trips: while the marketing carrier changes, the operating airline does not. They term this practice "virtual codesharing", and also find that such virtual codesharing itineraries are priced lower than the otherwise identical "online" trips: journeys that do not involve change in marketing carrier. Bamberger et al. (2004) also find that codesharing decreases fares on the affected US domestic routes. They attribute this effect to increased competitive pressures following the establishment of the partnership. Data availability for the US domestic market also allows - unlike for international routes - structural econometric analysis. Such studies are offered by Gayle (2008) and Armantier and Richard (2008).

\section{Benefits of Airline Partnerships}

\subsection{Double Marginalization}

Early applications for codesharing and antitrust immunity emphasized the complementary nature of an interline itinerary: a trip that consists of two or more segments that are operated by different airlines. It was further suggested that cooperation between the providers of the two complementary flight segments would result in a lower price for the interline trip as compared to the case where such cooperation would not be allowed. The well-known double marginalization result was invoked for this purpose: when two monopolists cooperate in pricing the composite good that consists of two complementary products, the price will be lower than in the case where each monopolist prices its component separately.

Applying this reasoning to airline cooperation, we can suggest that the pricing of interline trips changes fundamentally when codesharing is implemented; and pricing may change when antitrust immunity is granted to the airlines that operate a codesharing agreement. This is in line with what the academic literature indicates. Further, the empirical studies have demonstrated that antitrust immunity appears to reduce the interline fares to a greater extent than does codesharing alone. At the same time, there is no clear theoretically sound argument for why this should be so. But one mechanism could be that the antitrust immunity yields higher load factors, with the airlines' passing cost savings to the passengers-yet, it is not clear why this theoretically should be so. In fact, while cases of no cooperation and codesharing with antitrust immunity can be modelled in a relatively straightforward way, the intermediate case of codesharing without immunity has not been properly discussed in the literature.

Overall, as far as the removal of double marginalization is concerned, the central policy issue, in my opinion, is understanding whether and to what extent antitrust immunity can further reduce interline fares, as compared to simple codesharing. 
Empirically, this effect is indeed present; however, the exact mechanism that underlies the price decrease needs further examination.

I can suggest the following ways for antitrust immunity to put downward pressure on interline fares:

- Partner airlines' ability to use codesharing arrangements, which were off-limits to them without antitrust immunity; this could be the case, for instance, if antitrust immunity allows the possibility for the airlines to switch from blocked space to free-sale codesharing.

- Partner airlines' ability to set fares jointly for interline trips without codesharing. Antitrust immunity should technically allow the airlines to set prices jointly for interline trips that involve a change of both operating and marketing carrier: the interline trips that do not technically involve codesharing as described above.

- Partner airlines' ability to take full advantage of codesharing arrangements: genuinely more complete removal of double marginalization. There is, however, no clear model that would allow us to compare the extent of removal of double marginalization under codesharing with and without antitrust immunity.

\subsection{Product Quality}

With respect to the impact of airline partnerships on non-price product characteristics, the following effects are relevant: first, partnerships can yield increased frequency of flights between the partner airlines' hub airports. In the most extreme cases, codesharing causes the emergence of such non-stop services. For instance, Amsterdam-Detroit services might not be sustainable without codesharing agreement between KLM and Northwest, and later Delta. In the same fashion, cessation of an alliance can lead to such non-stop flights being discontinued: this is what happened to Austrian Airlines' Vienna-Atlanta service after its alliance with Delta fell apart in 2000. Even if additional seats on such non-stop flights are filled with connecting passengers, travellers who fly non-stop between the hubs still benefit, as they are now more likely to be able to take a flight that is closer to their most preferred departure time.

Partnerships can lead to better scheduling coordination. This reduces the total travel time, and can increase demand for the allied services. Bilotkach (2007a, b, c) shows that codesharing that is coupled with antitrust immunity leads to better scheduling coordination as compared to a partnership without immunity. Further, alliance membership can increase the value of the alliance member's frequent flier programs, as travelers now have more options for earning and redeeming their miles.

The above issues should be examined from a somewhat different angle in light of the recent consolidation events, which led to effective mergers of alliance activities following the airline mergers. Consider as an example Delta Air Lines' acquisition of Northwest: even if this event does not change the number of non-stop flights from Delta hubs to Paris and Amsterdam, the following things can happen:

First, changes in scheduling could lead to changes in effective frequency of service on individual one-stop markets: for instance, where connections to some 
airports could have been available via both Amsterdam and Paris prior to the merger, the merger could lead to the emergence of endpoints, connections to which are available via only one of these airports, which thus diminishes effective competition.

Second, by offering more route options between the same endpoints, the alliance-especially within a trans-Atlantic JV-will get more opportunities to pricediscriminate across these route options: for example, an option with shorter connecting time may be priced higher. That is, competition between two potentially vertically differentiated products will be replaced by a multiproduct monopolist- to the extent that is allowed by competition with other alliances-which is generally detrimental for consumer welfare.

\subsection{Efficiency}

The efficiency benefits of airline cooperation involve a reduction of the fixed costs through cost synergies that are achieved through the shared use of airport facilities and joint marketing and other operations-as well as a reduction of variable costs that are due to increased load factors, working through economies of traffic density. These benefits have been frequently alleged by applicants for antitrust immunity, and assumed by the regulators when approval was granted. However, in the academic literature there is no empirical study of which I am aware that quantifies these efficiency benefits. Further, it appears that as the airlines request more freedom in the cooperative setting of prices, frequencies, and schedules, they increasingly emphasize efficiency benefits as compared to the removal of double marginalization to rationalize their requests.

I have indicated above that the reduction of variable cost through the exploitation of economies of density will likely be directly related to the extent of the removal of double marginalization. That is, this particular efficiency gain is likely to be associated with codesharing/antitrust immunity/ joint ventures. In this respect, the following questions arise:

- What is the size of the cost reduction effect that is due to economies of traffic density? Available estimates are dated. Caves et al. (1984) suggested that a 10\% increase in load factor decreases the airline's total cost by about 2.5\%: if an alliance increases its load factor from 70 to $90 \%$, this would decrease the total cost by about 7\%). Brueckner and Spiller (1994) suggest a $3.75 \%$ decrease in marginal cost per $10 \%$ increase in load factor.

- Do joint ventures yield economies of density benefits beyond what is achieved via codesharing and antitrust immunity?

\section{Potential Anti-competitive Effects of Airline Partnerships}

The most widely recognized-both in the academic literature and by policy-makers-potential anti-competitive effect of airline cooperation is the reduction of competition by parallel alliances-especially where the partnership is covered by 
antitrust immunity. This concern effectively prevented the American Airlines/British Airways partnership from obtaining antitrust immunity until 2010, and led to the emergence of carve-outs for the overlapping parts of the partner airlines networks as a remedy in cases where antitrust immunity was granted.

Bilotkach and Hüschelrath (2011) further suggest the following potential anticompetitive effects of cooperative agreements between the airlines: first, airline alliances can create entry barriers by increasing the required scale for an airline to compete successfully with the incumbents. At this time, this appears to be a larger issue for the trans-Atlantic market than for such important segments of the global airline industry as the North America/Asia, EU/Asia, and EU/Australia markets. For the latter, the Gulf carriers Emirates and Etihad have been able to establish themselves as important carriers while staying out of the global alliances.

Second, airline cooperation-especially partnerships that are covered by antitrust immunity, and joint ventures - can create the potential for market foreclosure. The potential for market foreclosure arises as the airlines become unwilling to accept interline traffic from carriers that are outside of the partnership. This eventually leads to the outside carriers' reducing frequency and passenger volumes on flight segments to/from hub airports of the airlines that operate under immunity. One important implication of market foreclosure is that this effect can potentially decrease competition on all of the routes that originate at the hub airports of the airlines that participate in the alliances that are covered by antitrust immunityincluding one-stop markets that originate at such hubs (e.g., Amsterdam/Phoenix route). After the granting of antitrust immunity to the American Airlines/British Airways partnership (within the relevant joint venture), most of the non-stop transAtlantic flight segments involve at least one hub airport of a carrier, which is a member of the immunized alliance. What looks like market foreclosure, however, may amount to network optimization by the alliance members: for example, American Airlines does not send as many passengers to Paris as before because it channels more traffic via London.

Third, airline partnerships - especially those that operate under antitrust immunity-can create an environment that is more conducive to collusive behavior. Immunized partnerships stipulate a higher degree of cooperation as compared to more arms-length relationships, and are potentially more stable. This concern is (in my opinion) especially relevant given the current structure of the trans-Atlantic airline market, as recent airline consolidation events have led to several previously important competitors' leaving the industry. The relationship between the number of competitors and the ease of collusion is quite well established in the industrial organization literature.

Airline partnerships can have implications for the partner airlines' network development: specifically, it has been empirically demonstrated for the US airline industry that an airline is less likely to enter with non-stop service in those markets that it serves with a one-stop flight (Dunn 2008). If we apply this logic to the airline partnerships: an airline that enters a partnership-especially where antitrust immunity is present-may choose to put on hold its plans to open up new trans-Atlantic routes, or even close down some of the segments in its network, choosing instead to channel the traffic via its partner's hub. Smaller carriers that operate within an alliance-such 


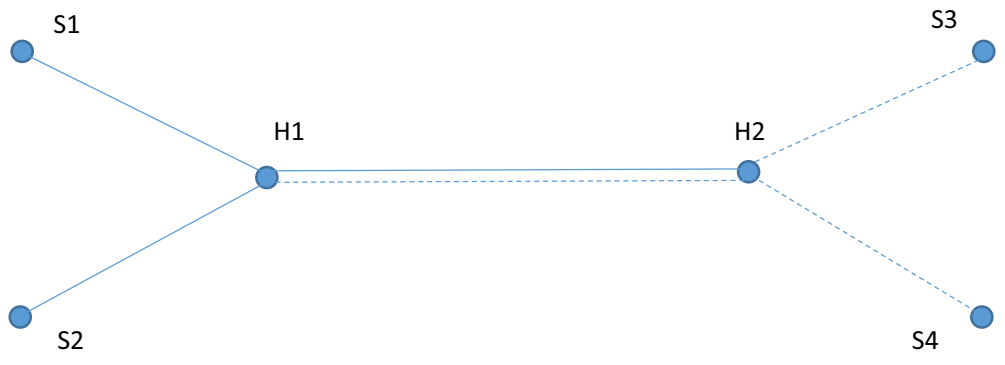

Fig. 2 Simple network structure with two partner airlines

as, for instance, Eastern European airlines-may concentrate on feeding traffic to their larger alliance partners instead of developing their own networks.

\section{Issues Solved and Unsolved: Theoretical Analysis}

The economics of codesharing seems simple enough at first glance: airlines sell seats on each other's flights, and if they are unable to directly coordinate pricesthere is no antitrust immunity-they at least could set different sub-fares for their partner airlines' interline passengers as opposed to the passengers who connect from outside the alliance network. Cooperation also increases flight load factors, which reduces per-passenger cost through economies of traffic density. Fixed costs could also decrease through increased efficiency: due to, for instance, joint use of airport facilities or joint marketing efforts.

Codesharing with antitrust immunity - joint price setting for the interline tripsis essentially a version of the removal of double marginalisation. The segments in the interline itinerary-operated by different alliance partners-are nothing but the two complementary products, and the classical result of a lower price under coordination applies. In the same way, coordination of service quality parameters-such as scheduling — could lead to higher product quality-more convenient schedules for the interline passengers-following Economides (1999).

Adding economies of traffic density to the picture complicates the story somewhat. This phenomenon is typically included in the theoretical models as marginal cost that is decreasing in traffic on a segment of the airline's network; a linear relationship between cost and traffic is typically assumed. While this formulation seems simple, the analysis actually gets very tedious very quickly. Consider a simple network structure, as in Fig. 2 below, which is adopted from Brueckner (2001). Here we have two airlines operating overlapping hub and spoke networks. Traffic on, for instance, $\mathrm{H} 1-\mathrm{H} 2$ segment of this network will include passengers traveling in H1-H2, H1-S3, H1-S4, S1-H2, S2-H2, S1-S3, S1-S4, S2-S3, and S2-S4 markets. While profit maximisation problems in this setting do have closed-form solutions, those are not amenable to conventional comparative statics. Starting from Brueckner's seminal work, a number of theoretical models of the effects of airline cooperation under immunity had to resort to simulation exercises: varying values of key 
parameters to evaluate the effects of partnerships on prices and welfare in different markets throughout the joint network.

In the network that is depicted in Fig. 2, the main trade-off here is between increased market power and lower per passenger cost in the $\mathrm{H} 1-\mathrm{H} 2$ market following establishment of the airline partnership. Brueckner's original simulation analysis demonstrated that-despite the market power effect that is present in the hub-to-hub market - the overall welfare effect of airline cooperation is positive.

Overall, the theoretical studies of airline partnerships have outlined the expected effects of airline cooperation, and provided an inspiration for the empirical work on this issue. The body of theoretical literature is, however, not always careful with how the specifics of airline partnerships are modelled. Most important, the theoretical distinction between alliances with and without antitrust immunity is weak. Many models assume price coordination between the airline partners: alliances with immunity. While those models do offer a comparison of alliance equilibrium with that without airline partnerships, they are usually silent on how alliances without immunity compare to partnerships that have antitrust immunity. Unfortunately, this is not a straightforward problem: Bilotkach (2005) attempted to introduce differentiation between alliances with and without immunity in a model of competing partnerships. The key assumption in his model is that without price coordination airlines are able to charge different sub-fares to interline passengers that connect to their flights from their partner airlines' flights, as compared to passengers who arrive from non-allied airlines' services. In that model, antitrust immunity did not reduce interline ticket prices beyond what was achieved by codesharing without immunity.

Another potentially interesting topic that is not covered by the theoretical body of work is the issue of potential differences in the outcomes of various types of codesharing agreements. Generally, codesharing agreements can be placed in a continuum between blocked space arrangements on one side and free sale agreements on the other. Under a blocked space arrangement, an airline obtains a fixed number of seats that it can sell on a partner airline's flight as its own. On such itineraries, the operating carrier might change, but the marketing carrier will not. Once this quota is exceeded, the airline must either stop selling tickets for that flight, or may still be able to feed interline passenger to its partner airline, with the latter selling those seats as its own at an appropriate sub-fare; in this case, the itinerary will show the change of both operating and marketing carrier. Under free sale arrangements, each airline can sell seats on the partner airline's flight as its own, as long as there are seats available: there are no capacity restrictions. Free sale arrangements are more flexible than blocked space ones, and they are becoming more popular as well. The implications of different forms of codesharing - both with and without antitrust immunity — would be an interesting issue for future research.

As was mentioned above, economies of traffic density are frequently present in theoretical models of airline partnerships. The simulation analysis that is present in those studies identifies regions of parameter values where coordination yields higher economic welfare than no coordination. These exercises are, however, not linked to the empirical studies of economies of density. This actually diminishes the usefulness of such otherwise rigorous and interesting research, in my opinion. On the one hand, it may be useful to know that the welfare ranking of various partnership 
arrangements can be different-depending on how strong are the economies of traffic density. However, policy makers would appreciate more specific answers.

Last (but not least), I consider the following two topics for theoretical exploration of airline partnerships to be the most promising and current: first, as the airline partnerships have been around for over quarter of a century, we can start addressing them in the context of repeated interaction: both within and between the airline alliances. Such issues as the stability of airline alliances, the potential for tacit collusion, and multimarket contact are worth examining. Second, we have in the last decade seen the emergence of a new, closer form of cooperation between airlines: joint ventures. So far these have largely eluded scholars' attention: We know relatively little about the JVs, except that they seem to be the closest thing that the airlines could have to a merger in the current institutional and regulatory environment. Fageda et al. (forthcoming) presents the first theoretical analysis that incorporates joint ventures. In their work, joint ventures are modelled as cost-sharing rather than revenue-sharing partnerships, which simplifies the matter quite a bit.

\section{Issues Solved and Unsolved-Empirical Work}

When addressing empirical studies of airline partnerships, it pays to note that here we have two distinct strands of literature: examinations of codesharing in US domestic and international markets. As we can see from the literature review, there has been a fair number of studies of US domestic codesharing over the years. Interestingly, while there have indeed been a number of such arrangements between the US carriers (one key way in which domestic codesharing differs from that on international flights is that antitrust immunity is not an option here), they are now virtually non-existent. When codesharing in the US domestic market was more common than it is now; the number of passengers who were actually covered by such services was quite insignificant. Interestingly, Ito and Lee (2007) discovered that most of the itineraries that involved codesharing were not even interline trips-a practice that they termed "virtual" codesharing.

Key inter-airline relationships that are currently in existence in the US domestic market are those between the major network airlines and the regional carriers. Various aspects of those relationships have been discussed in a series of studies by Lederman and Forbes (2009, 2010, 2013), and most recently by Tan (2017). The mainline/regional airline relationships are entirely different from the partnerships on which this paper focuses. Under codesharing, each partner airline is an independent entity that operates its network, retails tickets for its flights, and sets fares, etc. Mainline airlines, on the other hand, simply hire aircraft and crews of the regional airlines for flights on "thinner" routes. Regional airlines typically receive a fee per flight; the mainline carrier does all of the marketing, price setting, and retailing. Regional carriers typically operate fleets of smaller aircraft (that are also known as regional aircraft) with seat capacities that are substantially below those of Boeing 737 or Airbus A-320 narrow-body airplanes.

Most empirical studies of international airline partnerships have dealt with the estimation of the relevant price effects. As we noted above, theoretical studies 
pointed to a removal of double marginalisation on interline routes (Brueckner and Whalen 2000), while also suggesting the potential for increased market power and therefore higher prices on overlapping parts of the partner airlines' networks.

A key issue in empirical research on airline partnerships has been measurement of the incremental impact of antitrust immunity on airfares in different markets. The main dataset that is used for these studies has been the data bank DB1B International: a restricted access dataset that is very similar to the domestic DB1B dataset that is frequently used in empirical airline studies. DB1B International does not, unfortunately, present a complete picture of the market. One condition for granting of the antitrust immunity has traditionally been that the foreign airlines submit their tickets sold in the markets that are covered by the grant of such immunity to the DB1B dataset. However, these itineraries are not made available by the US Department of Transportation even to those individuals and organisations that obtain access to the DB1B International data bank. ${ }^{7}$ Thus, the dataset that is used in academic research includes online itineraries that are marketed by the US carriers, as well as the interline itineraries, where at least one segment has been marketed by a US airline. Tickets for itineraries, where all the segments have been marketed and operated by foreign airlines, are not included. This, in particular, limits the researchers' ability to set up a proper structural model to evaluate the effects of international partnerships under this framework. Structural econometric studies of US domestic codesharing are available in the literature (Gayle 2008; Armantier and Richard 2008).

The general consensus from empirical investigation of price effects of codesharing and antitrust immunity is that while antitrust immunity does yield lower prices for interline itineraries over and above the effect of codesharing, there is also evidence that this effect has become much smaller over time. While Brueckner's (2003) seminal investigation of this issue suggested that antitrust immunity yielded as much as $20 \%$ lower interline fares, the more recent study by Brueckner et al. (2011) found only small single-digit price effects at best.

As far as the empirical analysis of international airline partnerships is concerned, I believe that the following issues are worth investigating: first, the exploration should reach beyond the issue of the price effects of partnerships. If one studies the evolution of applications for antitrust immunity over the years, for instance, one visible trend is that the applicants over time tended to rely progressively less on the removal of double marginalisation in their attempt to persuade the authorities to grant them antitrust immunity. Arguments of operational efficiency benefits, the increased choice of routes for passengers, and better schedule coordination are increasingly brought to the front. Yet, there is no clear evidence that this is what the partner airlines have actually delivered. A recent investigation of joint ventures on the trans-Atlantic market by Bilotkach and Hüschelrath (2017) uncovered that while antitrust immunity is associated with higher load factors as compared to non-stop

\footnotetext{
7 The full DB1B International dataset has been used in an econometric study, which was commissioned by the European Commission's Directorate General on Competition in 2005. Due to the restricted access to these data, however, this study is not publicly available.
} 
flights that are not covered by immunity, joint ventures appear to yield lower load factors. Load factors can be considered a measure of efficiency. One could also argue, however, that higher load factors are an indication of lower product quality, as passengers increasingly find themselves on crowded planes, and airlines get less flexibility to re-accommodate their customers that missed their connections at the hub.

Systematic investigation of efficiency benefits might be difficult-if not impossible - without access to proprietary data; as noted above, perhaps the best publicly available proxy for efficiency is the data on the flight load factors. However, investigation of the effect of partnerships on schedule coordination and the availability of a variety of interline flight options within the partnerships can be attempted. The latter is an especially salient issue for multi-airline partnerships. One of the arguments that undelay (for instance) the application for four-airline antitrust immunity-which was submitted by Air France, KLM, Delta, and Northwest in 2007-was that with this immunity in place passengers would be able to travel via Amsterdam on the outward portion of their journey, and via Paris on the return trip. This is a fair point (and indeed, I have myself made several such journeys over the years). However, if the data were to show that the new partnership channels traffic to and from, say, Berlin, via Amsterdam, and passengers traveling to Vienna fly via Paris-whereas before the multi-airline antitrust immunity was adopted the two alliances competed for traffic to both European destinations - this would be evidence of potentially anticompetitive behaviour.

I mentioned in the previous section that theoretical investigations of airline partnerships should shed some light on the potential for tacitly collusive behaviour, repeated interaction, and other potential anti-competitive practices. This point is even more relevant for empirical research. Bilotkach and Hüschelrath (2013) provide the first such investigation; we focus on the potential for market foreclosure, which is brought about by antitrust immunity. There is potential for more work in this area.

Notwithstanding all of the points that were raised above, the key theme for empirical research on airline partnerships will in the near future be the assessment of incremental effects of joint ventures. The first paper in this area is Bilotkach and Hüschelrath (2017), which generally does not bring encouraging news. Joint ventures appear to have led to reduced efficiency, as well as fewer seats and smaller aircraft outside the routes between the joint venture partners' hub airports. The most interesting aspect of the current market structure on the trans-Atlantic routes is the co-existence of various forms of airline cooperation: from ad hoc codesharing agreements on specific markets to cost- and revenue-sharing joint ventures. Investigation of the current trans-Atlantic airline market could therefore yield a better general understanding of cooperative arrangements between firms that produce complementary products. 


\section{Going Forward: The Future of Airline Partnerships, and a Suggested Research Agenda}

The current setup with three global airline alliances appears stable, at first glance. Most of the large network carriers are indeed already members of one or the other alliance (with Emirates being a notable exception). Network carriers are known to have changed alliance affiliation; ${ }^{8}$ however, there have so far been no cases of airlines' abandoning an alliance strategy in favour of independent operations. The socalled low-cost carriers (LCCs)—-such as Southwest Airlines and JetBlue in the US; Ryanair, EasyJet, Wizzair, and Norwegian in Europe; and Air Asia, Lion Air, and JetStar in Australasia-focus predominantly on the leisure market segment. Some of the LCCs operate mostly or even exclusively point-to-point networks. Attempts at building both LCC-LCC and LCC-network-carrier partnerships have so far been unsuccessful. An airline that has no experience moving passengers within its network will find it pretty much impossible to coordinate transfers with a different carrier. Passengers are learning to self-connect between the point-to-point low-cost carriers' flights; but so far I see only limited attempts by the point-to-point airlines to respond to this trend by offering proper networks - I guess this would be too costly for them to do. Academic research on the issues of the point-to-point carriers' incentives to form partnerships is largely absent. There is some work on self-connection in the literature (Malighetti et al. 2008; Fageda et al. 2015). Altogether, these issues strike me as potentially interesting avenues for future research.

There are two ways for new global airline partnerships to emerge: first, such alliances can be formed by the airlines that are not currently members of any partnership. The joint venture between Virgin Atlantic and Delta Air Lines could be an example here. Note, however, that Delta-as a founding member of the Skyteam alliance - is unlikely to be interested in building up this partnership much further. At this time, the joint venture serves both members reasonably well. Delta is able to feed its passengers from behind-the-gateway US endpoints to Virgin Atlantic's extensive network of flights to London; otherwise, many of those passengers-if they wished to travel to London within Skyteam's network-would have to connect at both the US and European hub, while Virgin Atlantic can increase its load factors and benefit from the associated economies of traffic density. Etihad appears to have plans to develop a new alliance around its equity partnership with Alitalia; however, this ambition might be derailed by the dire financial state of Alitalia.

The second way that new alliances can emerge is by airlines leaving established partnerships. I believe that joint ventures have the potential to disrupt current alliances. Essentially, joint ventures are partnerships within partnerships, which create a set of "more equal than others" airlines. It is not that all airlines within an alliance are equal in the first place; rather, joint ventures create an incentive for the airlines that participate in those JVs to prioritise relationships with the airlines within the

\footnotetext{
${ }^{8}$ Most such changes, however, have preceded the mergers. For instance, Continental Airlines moved from Skyteam to Star alliance shortly before its merger with United, while US Airways left Star alliance for oneworld before being absorbed by American Airlines.
} 
joint venture as compared to relationships with the carriers that are outside of the joint venture-even though they might be in the same alliance. The intuition here is similar to that behind market foreclosure argument: partner airlines that are protected by antitrust immunity stop accepting interline passengers from the carriers that are outside of their partnership.

Last (but not least), I do not believe that transcontinental mergers that create mega-airlines will be feasible in the foreseeable future. Nationality clauses in bilateral air service agreements - as well as the foreign ownership restrictions that are present in the majority of jurisdictions-will ensure that codesharing-with antitrust immunity and joint ventures, where allowed-will remain the ways for the airlines to manage cross-border interline passenger air traffic.

We can also consider some upcoming technological changes, which could upset the current equilibrium. Specifically, the use of composite materials in aircraft manufacturing will make non-stop long-haul travel economically viable on thinner routes. For instance, British Airways has deployed its new Boeing 787 (Dreamliner) aircraft to such previously unserved US destinations as San Jose, Austin, Nashville, and New Orleans. Previously, passengers traveling from London to those destinations would have to connect to an American Airlines flight at one of the carrier's hubs. Next generation of narrow body Boeing and Airbus aircraft will also feature extended range; the Boeing 737 MAX will come with non-stop trans-Atlantic flight capability. Being able to offer flights to more long-haul destinations directly from their hubs, airlines may decide that partnerships are no longer as useful to them. As I noted above, partnerships on US domestic markets are not as important to large network carriers, because they are able to serve many destinations in the country by themselves.

Since airline partnerships are here to stay, should we continue devoting our time to studying them? And if so, what questions should we cover in the future research? In the previous sections, I have outlined some of the current gaps in our knowledge. Yet, those gaps should form only part of the future research agenda: we should also strive to understand how recent developments-most notably, joint ventures-have changed the incentives of the partner airlines, and what those changes mean for the future.

First, I believe that we should continue studying airline partnerships. From the previous sections, it should be clear that there are a number of things that we do not fully understand about the effects of codesharing, antitrust immunity, and joint ventures. We therefore have a limited ability to inform policy makers on the relevant issues. And, despite the above-identified threats to airline partnerships, there will be demand from the policy side for sound research on how to monitor and regulate alliances.

I believe that future work on airline partnerships should develop along the following lines of inquiry: first, we should gain a better understanding of the implications of different forms of codesharing, and more generally learn to distinguish between different forms of partnerships in our modelling exercises. I have discussed above the spectrum of codesharing arrangements that are used by the airlines: from blocked space to free sale agreements; however, we have yet to map those to standard Industrial Organization modelling approaches. On the one hand, this apparent 
sloppiness in theoretical research can be understood: after all, we do not usually have the data on the specifics of codesharing arrangements between the airlines. Yet, sound theoretical treatment of different codesharing approaches can go a long way toward informing the regulators-especially if there is correlation between codesharing arrangements and the regulatory environment: for example, if free sale arrangements are used by partners with antitrust immunity, while codesharing without immunity is predominantly of a blocked space nature.

More important, modelling exercises that are available in the literature do not make very clear the distinction between partnerships with/without antitrust immunity and joint ventures. Essentially, partnerships with immunity are often treated similarly to mergers — or cases of an airline's maximizing the sum of its profit and a share of its partner's profit. A clear distinction between these cases is still needednearly 20 years since the first models of airline cooperation were published. I tried offering a way of distinguishing between codesharing with and without immunity in my earlier work (Bilotkach 2005); however, my approach only works when there are competing alliances in the model. Furthermore, if anything, joint ventures are a closer arrangement to a merger than is antitrust immunity, so we can say that previous modelling approaches are more applicable now than they were when they were first developed.

I have previously discussed various effects of airline partnerships: both positive and negative. The empirical question of the link between those effects and different forms of partnerships still remains largely open. Could codesharing by itself yield removal of double marginalization, even without the partner airlines' being able to coordinate interline fares explicitly? After all, in practice nothing prevents an airline from defining a sub-fare to be charged when an interline passenger comes from the partner carrier. Do joint ventures yield additional cost savings as compared to the setup with antitrust immunity only? When applying for joint ventures, the airlines emphasized the concept of "metal neutrality": a simple example of how this works would be Delta Air Lines' locating its Boeing 757 in a European hub of its joint venture to operate trans-Atlantic flights to secondary airports (e.g., Providence, RI). Neither KLM nor Air France have $757 \mathrm{~s}$ in their fleet, and using wide-body aircraft would not work on such a route; and without joint venture, placing that Delta aircraft in Europe would not be feasible. This is a nice story, but we would need evidence that joint ventures do indeed yield additional efficiency benefits. Enough time has passed for such an investigation. Bilotkach and Hüschelrath (2017) represent the first attempt at addressing this question - and the "news" is not good for joint venture advocates. I hope and anticipate to see more work on this topic in the near future.

As joint ventures currently only include some of the alliance members, they have a potential to disrupt the current equilibrium. Alliance members left out of the joint ventures may seek to form different partnerships and joint ventures. Understanding the airlines' incentives in this respect looks like a promising avenue for future research: both theoretical and empirical. Existing research on the airlines' incentives to enter into alliances is scant (Gaggero and Bartolini 2012). Future studies in this area should take into account the dynamic nature of the airlines' decision-makingsomething that has so far been missing in the literature. 
The current setup with three alliances - and three large-scale joint ventures in the trans-Atlantic market-has been around for some time. It is therefore time for us to gain a better understanding of the effects of repeated interaction and multimarket contact; we need to understand whether airline partnerships contribute to a tacitly collusive environment in the industry. There is a sizeable body of literature that examines the effects of multimarket contact in the US domestic market (Evans and Kessides 1994; Singal 1996; Prince and Simon 2009; Bilotkach 2011; Ciliberto and Williams 2014). It would be interesting to see whether this relationship holds for international markets, and in what way: whether the relevant multimarket contact is between individual airlines, alliances, or joint ventures.

Last (but not least), I believe it makes sense to evaluate the effects of partnerships on non-price product characteristics and efficiency-if suitable data become available. The closest metrics that can be related to efficiency are load factors and flight delays. The former was used by Bilotkach and Hüschelrath (2017) to achieve an understanding of the efficiency effect of trans-Atlantic joint ventures. Bilotkach and Hüschelrath $(2013,2017)$ also evaluate the effect of antitrust immunity and joint ventures on flight frequency on non-stop trans-Atlantic routes. Future studies could examine such issues as schedule coordination (anecdotally, for instance, American Airlines' and British Airways' London-New York services have been spread more evenly throughout the day after their joint venture was approved); passenger flows within joint networks; network reorganization within alliances; and the impact of partnerships on the design of the partner airlines' customer loyalty programs.

Understanding how airline partnerships affect both joint network structure and actual passenger flows within the network is important for at least a few reasons: first, when approving closer cooperation between the airlines, the regulators should have a good idea about how the choices that are available to passengers will be affected. For instance, Dunn (2008) demonstrates (with the use of data for the US domestic market) that an airline that serves a market with one-stop service is less likely to open a nonstop flight between the two endpoints. The same could apply to partnerships-with new aircraft technology's acting as a countervailing force). Bilotkach et al. (2013) show that the merger between Delta and Northwest resulted in a network reorganization: with the largest hubs gaining prominence post-merger. Second, while partner airlines have repeatedly stated that closer cooperation will allow them to offer a wider menu of choices to their customers-for instance, one could travel from Chicago to Berlin via Amsterdam and back via Paris within the Skyteam trans-Atlantic joint venture network-it is important to check whether this is what the airlines actually do.

Ultimately, future research on airline partnerships should strive to inform policy making in this area. Reflecting our level of knowledge, regulatory interventions here have been rather simplistic: approving antitrust immunity unless partners' networks overlap too much; imposing carve-outs as remedies in a limited number of cases; and not reviewing antitrust immunity over time. As we gain a better understanding of the impact of partnerships on the airlines' competitive conduct, we should be able to conduct smarter, better informed policy.

Acknowledgements I am grateful to John Kwoka and Editor Lawrence White for the constructive comments, which improved this paper. Any errors and omissions remain my responsibility. 
Open Access This article is distributed under the terms of the Creative Commons Attribution 4.0 International License (http://creativecommons.org/licenses/by/4.0/), which permits unrestricted use, distribution, and reproduction in any medium, provided you give appropriate credit to the original author(s) and the source, provide a link to the Creative Commons license, and indicate if changes were made.

\section{References}

Adler, N., \& Hanany, E. (2016). Regulating inter-firm agreements: The case of airline codesharing in parallel networks. Transportation Research Part B, 84, 31-54.

Alderighi, M., Gaggero, A., \& Piga, C. (2015). The effect of code-share agreements on the temporal profile of airline fares. Transportation Research Part A, 79, 42-54.

Armantier, O., \& Richard, O. (2008). Domestic airline alliances and consumer welfare. RAND Journal of Economics, 39, 875-904.

Bamberger, G. E., Carlton, D. W., \& Neumann, L. R. (2004). An empirical investigation of the competitive effects of domestic airline alliances. Journal of Law and Economics, 47, 195-222.

Barla, P., \& Constantatos, C. (2006). On the choice between strategic alliance and merger in the airline sector: The role of strategic effects. Journal of Transport Economics and Policy, 40, 409-424.

Bilotkach, V. (2005). Price competition between international airline alliances. Journal of Transport Economics and Policy, 39, 167-189.

Bilotkach, V. (2007a). Complementary versus semi-complementary airline partnerships. Transportation Research Part B, 41, 381-393.

Bilotkach, V. (2007b). Airline partnerships and schedule coordination. Journal of Transport Economics and Policy, 41, 413-425.

Bilotkach, V. (2007c). Price effects of airline consolidation: Evidence from a sample of transatlantic markets. Empirical Economics, 33, 427-448.

Bilotkach, V. (2011). Multimarket contact and intensity of competition: Evidence from an airline merger. Review of Industrial Organization, 38, 95-115.

Bilotkach, V., Fageda, X., \& Flores-Fillol, R. (2013). Airline consolidation and the distribution of traffic between primary and secondary hubs. Regional Science and Urban Economics, 43, 951-963.

Bilotkach, V., \& Hüschelrath, K. (2011). Antitrust immunity for airline alliances. Journal of Competition Law and Economics, 7, 335-380.

Bilotkach, V., \& Hüschelrath, K. (2012). Airline alliances and antitrust policy: The role of efficiencies. Journal of Air Transport Management, 21, 76-84.

Bilotkach, V., \& Hüschelrath, K. (2013). Airline alliances, antitrust immunity, and market foreclosure. Review of Economics and Statistics, 95, 1368-1385.

Bilotkach, V., \& Hüschelrath, K. (2017). Balancing competition and cooperation: Evidence from transatlantic airline markets. Working paper.

Brueckner, J. (2001). The economics of international codesharing: An analysis of airline alliances. International Journal of Industrial Organization, 19, 1475-1498.

Brueckner, J. (2003). International airfares in the age of alliances: The effects of codesharing and antitrust immunity. Review of Economics and Statistics, 85, 105-118.

Brueckner, J., Lee, D., \& Singer, E. (2011). Alliances, codesharing, antitrust immunity, and international airfares: Do previous patterns persist? Journal of Competition Law and Economics, 7, 573-602.

Brueckner, J., \& Pels, E. (2005). European airline mergers, alliance consolidation, and consumer welfare. Journal of Air Transport Management, 11, 27-41.

Brueckner, J., \& Proost, S. (2010). Carve-Outs under airline antitrust immunity. International Journal of Industrial Organization, 26, 657-668.

Brueckner, J., \& Spiller, P. (1994). Economies of traffic density in the deregulated airline industry. Journal of Law and Economics, 37, 379-415.

Brueckner, J., \& Whalen, T. (2000). The price effects of international airline alliances. Journal of Law and Economics, 43, 503-545.

Caves, D. W., Christensen, L. R., \& Tretheway, M. W. (1984). Economies of density versus economies of scale: Why trunk and local service airline costs differ. RAND Journal of Economics, 15, 471-489.

Chen, Y., \& Gayle, P. (2007). Vertical contracting between airlines: An equilibrium analysis of codeshare alliances. International Journal of Industrial Organization, 25, 1046-1060. 
Ciliberto, F., \& Williams, J. W. (2014). Does multimarket contact facilitate tacit collusion? Inference on conduct parameters in the airline industry. RAND Journal of Economics, 45, 764-791.

Czerny, A. (2009). Code-sharing, price discrimination and welfare losses. Journal of Transport Economics and Policy, 43, 193-212.

Czerny, A., van den Berg, V. C., \& Verhoef, E. T. (2016). Carrier collaboration with endogenous fleets and load factors when networks are complementary. Transportation Research Part B, 94, 285-297.

Dunn, A. (2008). Do low-quality products attract high-quality entry: Multiproduct firms and non-stop entry in airline markets. International Journal of Industrial Organization, 26, 1074-1089.

Economides, N. (1999). Quality choice and vertical integration. International Journal of Industrial Organization, 17, 903-914.

Evans, W. N., \& Kessides, I. N. (1994). Living by the "golden rule": Multimarket contact in the U.S. airline industry. The Quarterly Journal of Economics, 109, 341-366.

Fageda, X., Flores-Fillol, R., \& Theilen B. (forthcoming). Hybrid cooperation agreements in networks: The case of the airline industry. International Journal of Industrial Organization.

Fageda, X., Suau-Sanchez, P., \& Mason, K. J. (2015). The evolving low-cost business model: Network implications of fare bundling and connecting flights in Europe. Journal of Air Transport Management, 42, 289-296.

Flores-Fillol, R., \& Moner-Colonques, R. (2007). Strategic formation of airline alliances. Journal of Transport Economics and Policy, 41, 427-449.

Gaggero, A., \& Bartolini, D. (2012). The determinants of airline alliances. Journal of Transport Economics and Policy, 46, 399-414.

Gayle, P. (2008). An empirical analysis of the competitive effects of the delta/continental/ northwest code-share alliance. The Journal of Law and Economics, 51, 743-766.

Ito, H., \& Lee, D. (2005). Domestic codesharing practices in the US airline industry. Journal of Air Transport Management, 11, 89-97.

Ito, H., \& Lee, D. (2007). Domestic code sharing, alliances, and airfares in the U.S. airline industry. Journal of Law and Economics, 50, 355-380.

Jiang, C., Wan, Y., \& D’Alfonso, T. (2015). Strategic choice of alliance membership under local competition and global networks. Journal of Transport Economics and Policy, 49, 316-337.

Lederman, M., \& Forbes, S. (2009). Adaptation and vertical integration in the airline industry. American Economic Review, 99, 1831-1849.

Lederman, M., \& Forbes, S. (2010). Does vertical integration affect firm performance? Evidence from the airline industry. RAND Journal of Economics, 41, 765-790.

Lederman, M., \& Forbes, S. (2013). Contract form and technology adoption in a network industry. Journal of Law Economics and Organization, 29, 385-413.

Malighetti, P., Paleari, S., \& Redondi, R. (2008). Connectivity of the European airport network: "Selfhelp hubbing" and business implications. Journal of Air Transport Management, 14, 53-65.

Oum, T., Park, J., \& Zhang, A. (1996). The effects of airline codesharing agreements on firm conduct and international air fares. Journal of Transport Economics and Policy, 30, 187-202.

Park, J.-H. (1997). The effect of airline alliances on markets and economic welfare. Transportation Research Part E, 33, 181-195.

Park, J.-H., \& Zhang, A. (2000). An empirical analysis of global airline alliances: Cases in the north atlantic markets. Review of Industrial Organization, 16, 367-384.

Prince, J., \& Simon, D. (2009). Multimarket contact and on-time performance in the U.S. airline industry. Academy of Management Journal, 52, 336-354.

Singal, V. (1996). Airline mergers and multimarket contact. Managerial and Decision Economics, 17, 559-574.

Tan, K. M. (2017). Outsourcing and price competition: An empirical analysis of the partnerships between legacy carriers and regional airlines. Review of Industrial Organization. https://doi.org/10.1007/ s11151-017-9610-z.

Wan, X., Zou, L., \& Dresner, M. (2009). Assessing the price effects of airline alliances on parallel routes. Transportation Research Part E, 45, 627-641.

Whalen, W. T. (2007). A panel data analysis of code sharing, antitrust immunity and open skies treaties in international aviation markets. Review of Industrial Organization, 30, 39-61.

Zhang, A., \& Zhang, Y. (2006). Rivalry between strategic alliances. International Journal of Industrial Organization, 24, 287-301.

Zou, L., Oum, T., \& Yu, C. (2011). Assessing the price effects of airline alliances on complementary routes. Transportation Research Part E, 47, 315-332. 